Thorax, 1979, 34, 177-186

\title{
Electron microscopy of the plexiform lesion
}

\author{
PAUL SMITH AND DONALD HEATH
}

From the Department of Pathology, University of Liverpool, Liverpool, UK

ABSTRACT Pulmonary arteries from a case of plexogenic pulmonary arteriopathy were studied with the electron microscope. Many muscular pulmonary arteries showed intimal fibrosis of concentric or "onion-skin" type. The cells embedded within this fibrosis resembled smooth muscle but since they also possessed some features of fibroblasts we refer to them as myofibroblasts. Myofibroblasts also occurred in plexiform lesions together with fibroblasts and "fibrillary cells". These fibrillary cells contained numerous, prominent filaments with a random orientation. They lined the vascular channels of the plexiform lesions as well as being present within the stroma. They appeared to phagocytose fibrin and then to organise the plexiform lesion into a fibrous scar. Fibrillary cells closely resemble vasoformative reserve cells and the cells of the cardiac myxoma and so-called "papillary tumour" of heart valves. They may, therefore, be primitive multipotential cells found throughout the entire cardiovascular system.

Plexogenic pulmonary arteriopathy is the term adopted by a Working Party of the World Health Organisation in 1974 to describe that form of hypertensive pulmonary vascular disease that has a potential for developing plexiform lesions (Hatano and Strasser, 1975). It is the severe, and probably irreversible, form that is found in association with large congenital cardiac shunts and with primary pulmonary hypertension. It also occurs in rare cases of cirrhosis of the liver or obstruction to the portal vein that have become associated with pulmonary hypertension (Naeye, 1960; Segel et al, 1968; Saunders et al, 1979). The histopathological features of this condition comprise medial hypertrophy of muscular pulmonary arteries, muscularisation of pulmonary arterioles, intimal fibroelastosis of concentric or onion-skin type, necrotising arteritis, and plexiform lesions. These last lesions have two components. The first consists of a sac produced by dilatation of a side branch or termination of a muscular pulmonary artery, usually proximal to an occluded segment of the parent vessel; it thus comprises one type of "dilatation lesion." The second component is a cellular proliferation within the sac, the numerous cells being arranged into an interwoven mass with vascular channels running tortuously through them. Since they resemble a vascular plexus, the lesion is described as plexiform.

Little is known of the nature of the proliferating cells and hence of the pathogenesis of the plexiform lesion. Recently we had the opportunity to examine the ultrastructure of plexogenic pulmonary arteriopathy in a young Indian man who died from pulmonary hypertension and associated pulmonary vascular disease complicating cavernomatous transformation of the portal vein (Saunders et al, 1979). Since a post-mortem examination was performed only 12 hours after death we had the opportunity to determine the nature of the cells that form plexiform lesions.

\section{Materials and methods}

The case history, morbid anatomy, and histopathology of this case are presented in detail (Saunders et al, 1979).

At necropsy small blocks of lung tissue were taken and cut up with a razor blade into $1 \mathrm{~mm}$ cubes. They were fixed in $3 \%$ glutaraldehyde in phosphate buffer at $4^{\circ} \mathrm{C}$ overnight and then stored in buffered isotonic sucrose solution. The right lung was distended with buffered glutaraldehyde for 12 hours then washed and stored in sucrose solution. Material for electron microscopy was also taken from this tissue but, since it was already fixed, larger blocks, $5 \mathrm{~mm}$ square, could be taken to increase the chances of including a plexiform lesion. The tissue for electron microscopy in both cases was post-fixed in aqueous $2 \%$ osmium tetroxide for one hour, dehydrated in ethanol, stained with uranyl acetate, and embedded in Araldite. Sections $1 \mu \mathrm{m}$ in thickness were stained with toluidine blue for the selection of 
suitable fields. Thirty sections were chosen from about 100 blocks for examination. Fine sections were cut with an LKB Ultratome III, stained with lead citrate; and examined with an AE1 6B electron microscope.

\section{Results}

Despite the fact that the lung tissue was obtained several hours post-mortem, there was good preservation of cellular detail in most cells. Only the mitochondria were larger and paler than usual indicating early autolytic change.

Three types of pulmonary vascular lesion were examined. The first was intimal proliferation of the muscular pulmonary arteries staining red with Van Gieson's stain and thus having the appearances that would be described on light microscopy as "intimal fibrosis." The other two types of vascular lesion were plexiform lesions and veinlike, dilated side branches of muscular pulmonary arteries. These are considered below.

INTIMAL FIBROSIS

The media of arteries affected by intimal fibrosis contained numerous, circularly-orientated smooth

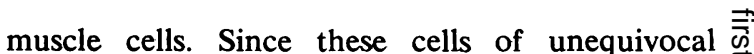
nature acted as a yardstick against which we $\overline{0}$ judged others that had certain features of smooth muscle cells, we shall first describe them in detail. Smooth muscle cells had an electron-dense cytoplasm consisting mainly of numerous myofilaments (fig 1). These were orientated predominantly in the longitudinal axis of the cell. Myofilaments ran parallel to one another. They occurred in two thicknesses comprising short, stout myosin fila- o ments and much more numerous, longer, finer $\overrightarrow{\vec{x}}$ actin filaments. There was no geometrical arrange- $\dot{\omega}$ ment of filaments such as occurs in striated muscle. At intervals, apparently randomly within the cell, the fine filaments converged on cigar- $\searrow$ shaped, electron-dense focal condensations (fig 1). $\bigcirc$ A third type of filament could occasionally be identified. This was intermediate in diameter be- $D$ tween actin and myosin and was particularly evident in the vicinity of focal condensations and attachment points.

The nucleus of smooth muscle cells was centrally placed, elongated, and irregular in outline. Organelles such as mitochondria and endoplasmic reticulum were scanty and restricted mainly to the perinuclear zone. The edge of

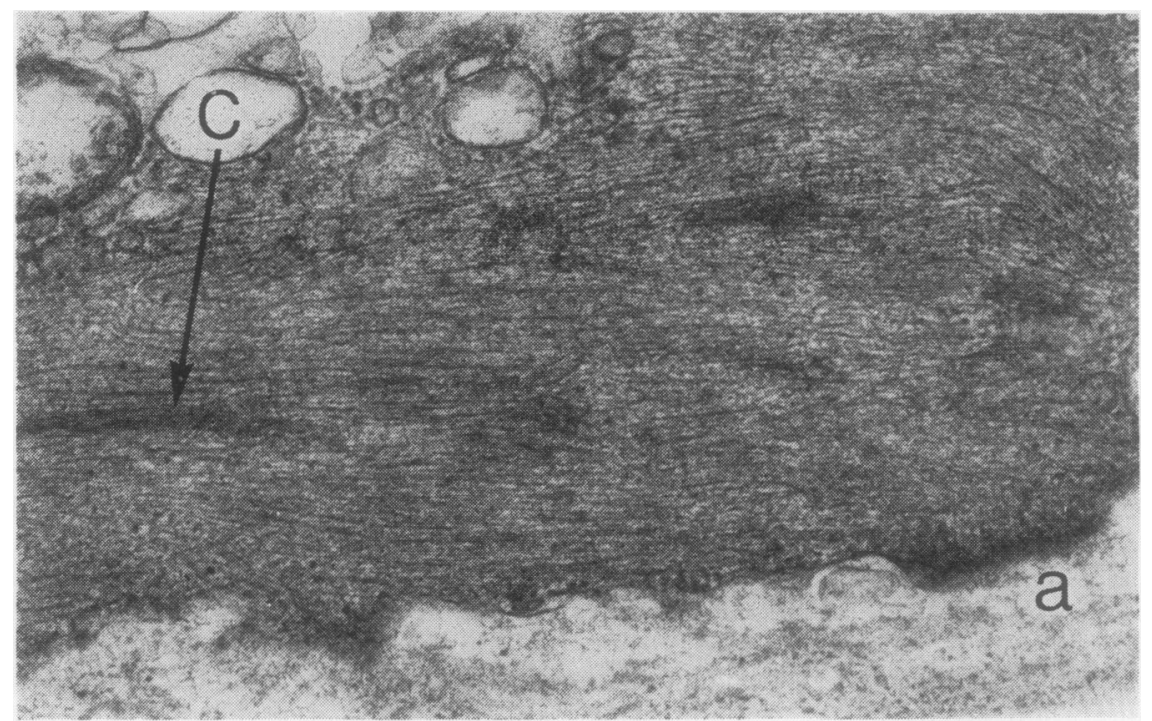

Fig 1 Smooth muscle cell from media of a muscular pulmonary artery showing normal features of this type of cell. Cytoplasm is filled with parallel myofilaments. Bolder filaments are composed of myosin whereas thinner actin filaments form a barely discernible feltwork between them. In places myofilaments converge at dark, cigar-shaped focal condensations (c). Edge of cell contains a dark plaque (a) in which cell membrane is indistinct. This is an attachment point where myofilaments are believed to be anchored to plasmalemma and basal lamina. Latter shows as an amorphous layer adjacent to outer margin of cell (Electron micrograph $\times 41900$ ). 
smooth muscle cells was surrounded by an amorphous or granular basal lamina that tended to merge with the intercellular ground substance. The plasmalemma contained numerous micropinocytotic vesicles, but these were interrupted at intervals by electron-dense plaques called attachment points (fig 1). In these regions the cytoplasm was exceptionally dense and dark with a similar focal increase in density of the adjacent basal lamina. The intervening plasmalemma was often indistinct in these regions, which are commonly held to be the points where myofilaments are anchored to the cell membrane and the basal lamina.

In pulmonary arteries affected by intimal fibrosis the intima contained numerous cells resembling smooth muscle (fig 2). Thus they possessed a central nucleus, peripheral basal lamina, and contained prominent focal condensations, attachment points, and microfilaments (fig 3). The latter were mutually parallel and comprised filaments of two thicknesses similar to those in medial smooth muscle. Unlike the smooth muscle of the media, however, these myofilaments did not occupy all of the cell cytoplasm. Instead they were arranged into short bundles with areas of clear cytoplasm between (figs 3-5). Focal condensations were large irregular dark areas of indeterminate shape as contrasted to their

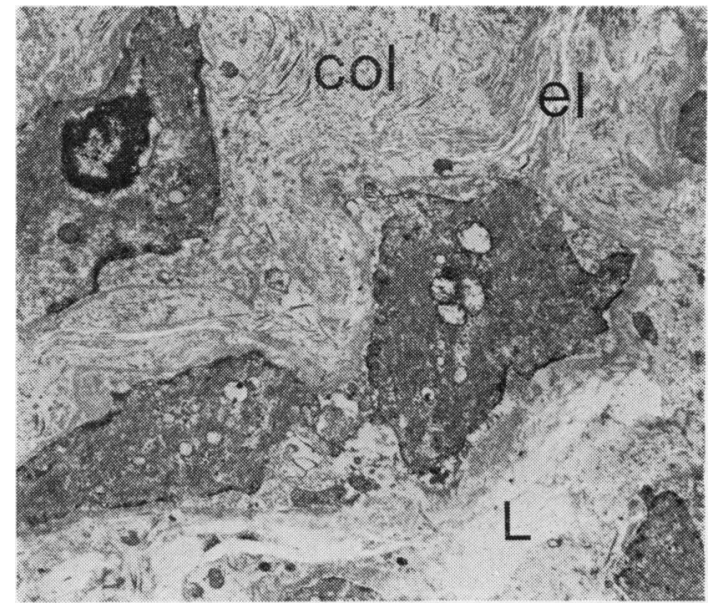

Fig 2 Muscular pulmonary artery with onion-skin intimal fibrosis. Internal elastic lamina $(L)$ can be seen and beyond this is intimal fibrosis consisting of cells that resemble smooth muscle. Between them is a mixture of elastin ( $\mathrm{el})$, collagen fibres (col), and amorphous ground substance $(E M \times 5100)$.

typically cigar-shaped equivalents in the media (fig 5). Attachment points too were different in that they were irregular and sometimes divorced from the myofilaments. Mitochondria were numerous, and the perinuclear zone was more

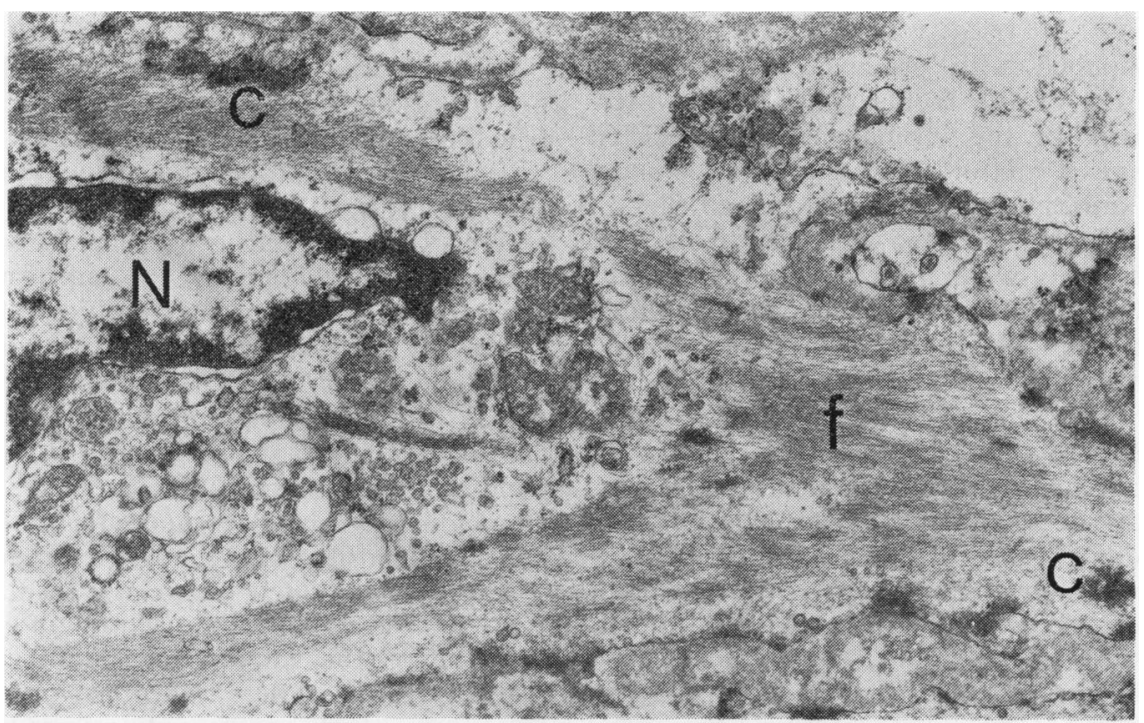

Fig 3 Muscular pulmonary artery. Detail of one of intimal cells. It has a central nucleus $(N)$ surrounded by extensive endoplasmic reticulum and mitochondria. Numerous parallel filaments $(f)$ are present in the cytoplasm but these are shorter and more scanty than in normal smooth muscle. Focal condensations (c) are prominent and irregular $(E M \times 15600)$. 


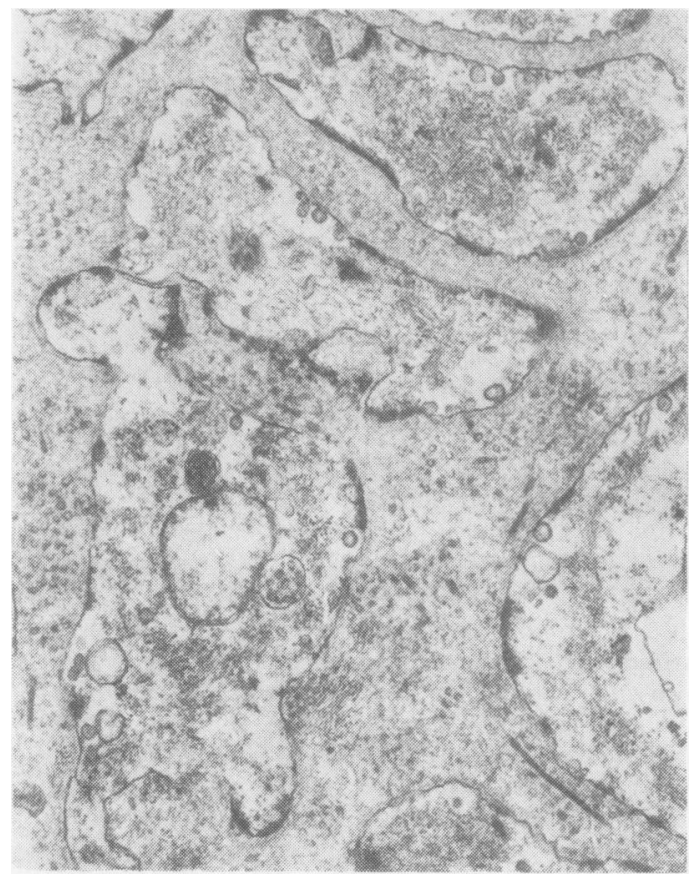

Fig 4 Muscular pulmonary artery. Several cells from intimal fibrosis are shown. They contain microfilaments arranged in short bundles with pale cytoplasm between. Note dark attachment points at cell periphery some of which are isolated from microfilaments $(E M \times 18750)$.

profusely supplied with organelles than in the smooth muscle of the media (fig 3). The intercellular matrix of the intimal fibrosis consisted of a disorganised mixture of elastin, fine collagen fibrils, and amorphous ground substance (fig 2), which tended to be arranged in concentric layers. Typical fibroblasts were scarce. Endothelial cells that lined the intimal fibrosis sometimes contained scanty, fine filaments of uniform diameter and microtubules.

\section{PLEXIFORM LESIONS}

The ultrastructure of plexiform lesions was complex. It had two main components. The first was a limiting dilated sac formed by dilatation of a side branch or a termination of a muscular pulmonary artery showing distal occlusion by fibrosis or fibroelastosis. The second component was a proliferation of connective tissues within this sac. These proliferated tissues themselves comprised three elements-namely, a plexus of vascular channels lined by cuboidal cells, a mixed population of cells between the channels, and an acellular matrix.

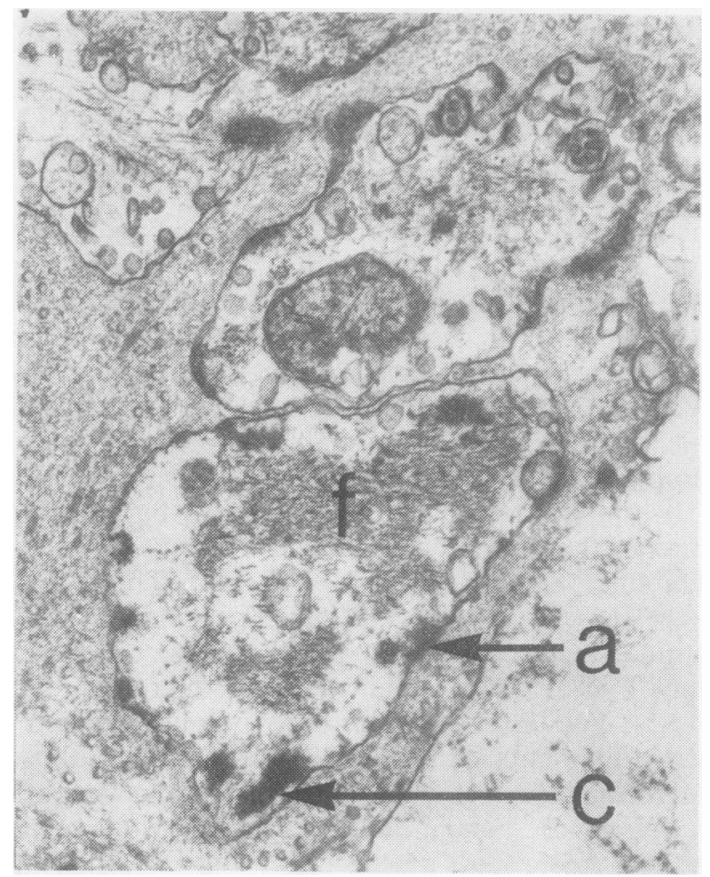

Fig 5 Muscular pulmonary artery. Intimal cells containing scanty bundles of short microfilaments $(f)$. Attachment points (a) and focal condensations (c) are dark, abnormally irregular, and often divorced from filaments $(E M \times 25000)$.

The cells that lined the vascular plexus superficially resembled plump endothelial cells. Unlike $\stackrel{\sim}{\times}$ true pulmonary endothelium, however, they lacked a basement membrane, micropinocytotic vesicles, and caveolae. Weibel-Palade bodies were also $ᄋ$ absent. Instead their cytoplasm often contained $₹$ numerous microfilaments of uniform thickness arranged in a haphazard fashion (fig 6). The $\rightarrow$ lumen of the vascular plexus contained erythrocytes and in some plexiform lesions a deposit of $\tilde{D}$ fibrin. Much of this was dense and amorphous but occasionally the characteristic fine cross- 0 banding of crystalline fibrin could be seen (fig 6). $\mathrm{\omega}$ In places fibrin had escaped from the channels? and was deposited between the intervening cells.

The cells situated between vascular channels $\overparen{\mathbb{D}}$ were of several types. Many of them were $\stackrel{\infty}{+}$ identical to the smooth muscle-like cells of the 0 intimal fibrosis. There were also numerous cells, $\frac{O}{\Phi}$ however, which contained microfilaments but $\stackrel{\odot}{\mathscr{Q}}$ which did not resemble smooth muscle. Rather $\stackrel{\mathbb{Q}}{\Omega}$ than attempt to ascribe a specific origin to these 0 cells we simply designate them "fibrillary cells." Microfilaments within fibrillary cells were con- 


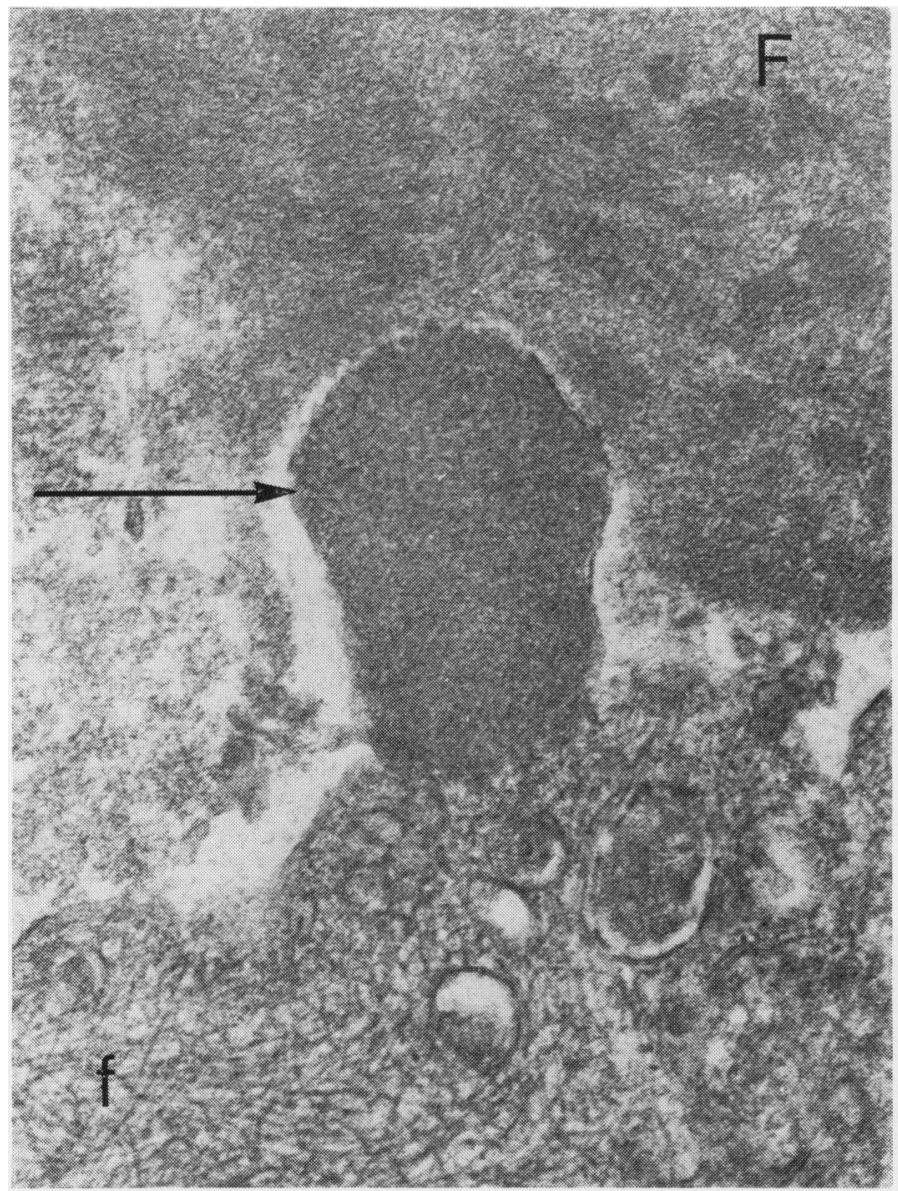

Fig 6 Plexiform lesion. A fibrillary cell lining a vascular channel contains numerous microfilaments $(f)$ arranged in a random fashion. Lumen of channel contains fibrin $(F)$ in which a characteristic periodicity can be discerned in places. A large piece of amorphous fibrin (arrowed) is in close contact with the fibrillary cell and is apparently entering its cytoplasm. Cell contains several dark inclusions that may be ingested fibrin $(E M \times 59120)$.

spicuous and of uniform thickness (fig 7). Their diameter was intermediate between that of the actin and myosin filaments in smooth muscle. They were not aligned with any particular axis of the cell but tended to be arranged in whorls (fig 7), or as an interlacing network (fig 6). The fibrils did not contain focal condensations or peripheral attachment points. Micropinocytotic vesicles were uncommon, as were organelles of any sort.

The third type of cell was the fibroblast. This contained a profuse rough endoplasmic reticulum of characteristically open pattern (fig 8), and was associated with fine collagen fibrils. The bulk of the intercellular matrix, however, consisted of amorphous or finely fibrillar material resembling the substance of basement membranes.

In a few plexiform lesions an unusually close association between fibrillary cells and deposits of fibrin was seen. In one instance a clump of fibrin was found apparently in the process of entering a fibrillary cell as if it were being phagocytosed by it (fig 6). Indeed several fibrillary cells were found containing irregular, dense bodies similar in appearance to the extracellular fibrin (fig 9). Definite proof that this was fibrin, however, was lacking because the fine cross banding could not be shown.

\section{VEIN-LIKE SIDE BRANCHES}

The dilated vein-like side branches of pulmonary arteries did not contain intimal fibrosis or fibrillary cells. Instead the smooth muscle cells of the media were finely attenuated due to dilatation of the vessel. Although greatly stretched, the smooth muscle cells had a normal cytoplasmic ultrastructure. The elastic laminae of these vessels were fragmented. The external elastic lamina was absent for much of the circumference of the vessel. The internal elastic lamina consisted 


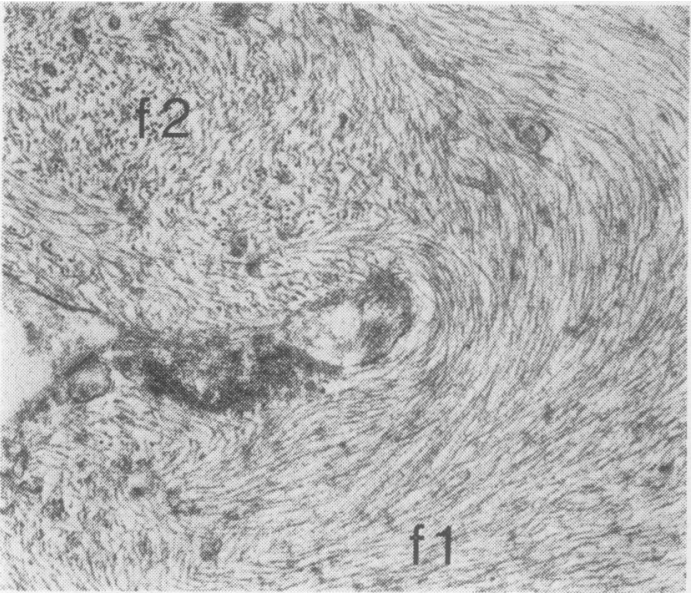

Fig 7 Plexiform lesion. A fibrillary cell containing numerous microfilaments of uniform diameter. Some of these are arranged in whorls (f1) orientated in plane of section, whereas other filaments $(f 2)$ are orientated at right angles to them and appear as a series of dots. Note that there are no focal condensations or attachment points $(E M \times 25000)$.

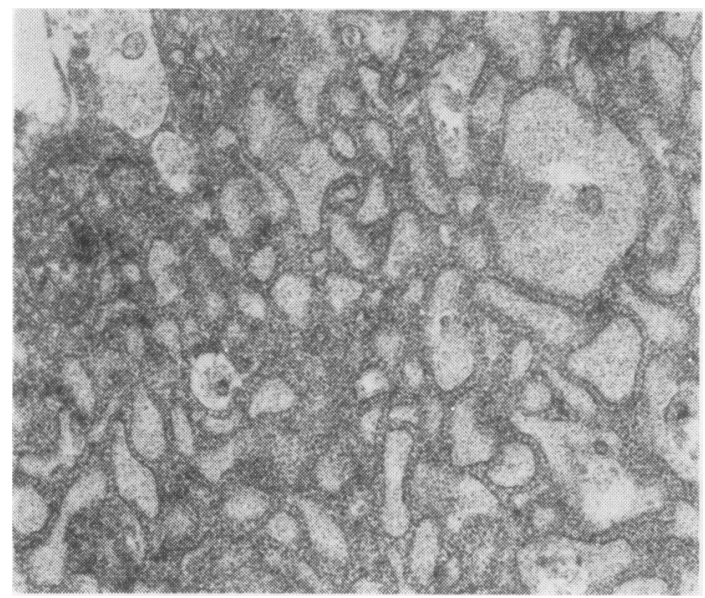

Fig 8 Plexiform lesion. A typical fibroblast with extensive rough endoplasmic reticulum with dilated cisternae containing a pale granular substance $(E M \times 17300)$

merely of a disjointed series of clumps of elastin. Within these clumps the elastin fibres were arranged in no specific direction and often had frayed edges. The ultrastructural appearances were consistent with gross dilatation of the vessels with rupture of elastic laminae.

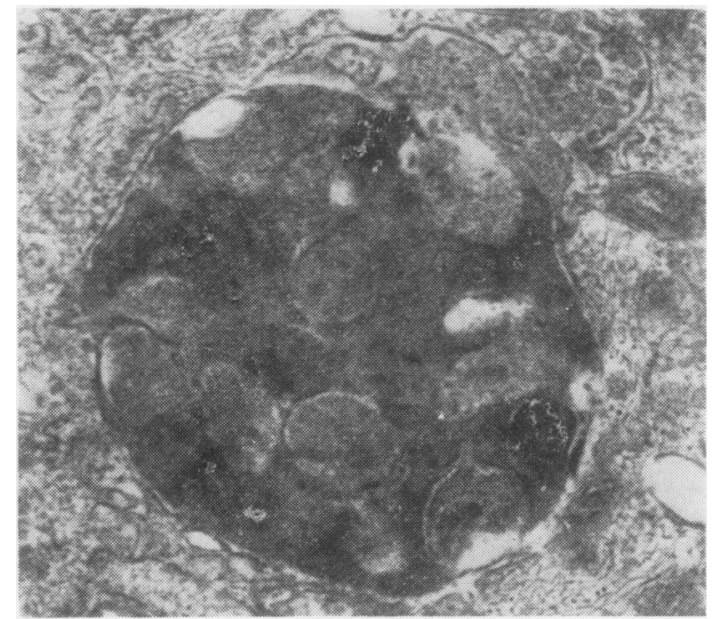

Fig 9 Plexiform lesion. Part of a fibrillary cell containing a large electron dense inclusion. This resembles extracellular fibrin but lacks its periodicity. It may represent fibrin ingested by fibrillary cell $(E M \times 36000)$.

\section{Discussion}

Electron microscopy has shown that the cellular component of the intimal fibrosis occluding pulmonary arteries closely resembles smooth muscle. Thus the intimal cells contain bundles of parallel myofilaments, focal condensations, attachment points, and are surrounded by a basal lamina. As we have noted above, however, they differ in several respects from the smooth muscle cells of the media. In particular their myofilaments are shorter and less numerous, and both attachment points and focal condensations are atypical.

Hatt et al (1959) described similar cells in the intima of pulmonary arteries in cases of pulmonary hypertension complicating congenital cardiac defects. They attributed their origin to altered endothelial cells. Identical cells appeared in the intima of pulmonary arteries in dogs with experimentally induced pulmonary hypertension (Esterly et al, 1968). In this study the intimal cells appeared to have migrated from the media and were hence believed to have been derived from smooth muscle. The latter possibility seems to be the most likely source of these cells since they are closely similar to cells that produce intimal fibrosis in renal arteries and arterioles in systemic hypertension (Spiro et al, 1965) and the cells that migrate into the intima after endothelial damage (Buck, 1961; Poole et al, 1971) or experimental atherosclerosis (Haust et al, 1960; Thomas et al, 1963; Parker and Odland, 1966). In all these 
papers except one (Haust et al, 1960) the origin of the intimal cells has been traced to the media. Indeed, there is strong evidence to suggest that the medial smooth muscle cell is multifunctional and is responsible for producing all the connective tissue elements of normal as well as diseased arteries (Wissler, 1968). Despite this evidence one cannot discount entirely the possibility that the intimal cells are derived from the endothelium. Structures resembling myofilaments have been seen in the endothelial cells of pulmonary arteries (Bensch et al, 1964) and in the aortic endothelium of hypertensive rats (Gabbiani et al, 1975). Actomyosin antigenically similar to that of the myometrium has been detected in normal systemic endothelial cells by immunofluorescence techniques (Becker and Murphy, 1969). We should point out, however, that we have been impressed by the lack of microfilaments in endothelial cells of the pulmonary trunk (Heath and Smith, 1979) and muscular pulmonary arteries (Smith and Heath, 1977) of the rat.

Although the intimal cells superficially resemble smooth muscle, it is doubtful whether they should be referred to as such since they are altered smooth muscle and are probably more closely related to the myointimal cell of Buck (1961) and the myofibroblast of Gabbiani et al (1972). We feel the latter term is to be preferred since the intimal cells in our case, and in other reports, are found in close association with, and hence presumably secrete, ground substance, collagen, and elastin. Furthermore they are not exclusively intimal since we have seen them within the media of pulmonary arteries with medial sclerosis and fibrinoid necrosis in rats given a diet of Crotalaria spectabilis seeds (Heath and Smith, 1978). They also occur in granulation tissue where they not only secrete collagen but cause contraction of the healing wound (Gabbiani et al, 1972).

Myofibroblasts were also numerous in plexiform lesions. This is to be expected since plexiform lesions are contiguous with arteries occluded by intimal fibrosis. Also the plexiform lesions in this case were at a moderately advanced stage in their development with the deposition of collagen and elastin among the cellular component. Plexiform lesions contained a type of cell, however, that was rarely encountered in the intimal fibrosis. This was the "fibrillary cell," which shared little in common with normal smooth muscle. Even its cytoplasmic filaments were more prominent and randomly arranged than in smooth muscle. We can only speculate as to the nature and origin of fibrillary cells. They are identical to the cells comprising the cardiac myxoma and so-called "papillary tumour of heart valves" (Stovin et al, 1973). Similar fibrillary cells are found normally in the heart and great vessels and have been designated "subendothelial vasoformative reserve cells" (Stein et al, 1969). The fibrillary cells of the plexiform lesion may be these vasoformative reserve cells that have accumulated within the dilatation lesions. If so, they must arrive there from the blood stream since we have never seen a fibrillary cell within the subendothelium of normal muscular pulmonary arteries. Alternatively, fibrillary cells may be derived from altered smooth muscle of the media in a manner similar to the myofibroblasts. Certainly we have seen fibrillary cells within the damaged media of pulmonary arteries affected with fibrinoid necrosis, suggesting a muscular origin of these cells (Heath and Smith, 1978). We cannot discount, however, the possibility that they originate from the endothelium for the same reasons discussed above in relation to myofibroblasts. Indeed, the origin of fibrillary cells is even more indeterminate since they share little in common with normal smooth muscle or endothelium.

Whatever their origin, fibrillary cells appear to be an important component of the plexiform lesion since they line the vascular channels as well as forming part of the stroma. They are probably responsible for secreting the mucopolysaccharide ground substance that is plentiful in plexiform lesions in the same manner as their counterparts do in the cardiac myxoma. As plexiform lesions age they become less cellular with an increased secretion of collagen and elastin until a fibroelastic scar is produced. It is conceivable that fibrillary cells undergo transformation into myofibroblasts and eventually fibroblasts. In our case the plexiform lesions were moderately advanced and hence comprised a mixed population of all three cell types. Perhaps young lesions are composed entirely of fibrillary cells.

In some plexiform lesions that we examined there was a strikingly close relationship between fibrillary cells and fibrin. Indeed fibrinoid necrosis is commonly associated with plexiform lesions (Wagenvoort et al, 1964). In the present study fibrin was observed to be apparently within the cytoplasm of fibrillary cells or else to be in the process of being phagocytosed by them. On light microscopy small deposits of fibrin were seen scattered among the plexiform lesions, but it was difficult to determine whether this was intracellular or not. However, we have examined younger plexiform lesions from other cases stained by various techniques to show fibrin. These lesions were highly cellular (fig 10) and contained large 
deposits of fibrin both within the media of the parent vessel and between the cells of the plexiform lesion (fig 11). Numerous small globules of fibrin, however, were also situated inside the cytoplasm of many of the cells constituting the plexiform lesion (fig 12). This presents the interesting possibility that plexiform lesions develop as a response to fibrin accumulating within a dilated sac. On this basis, fibrinoid necrosis precedes the development of plexiform lesions which involve an immigration of fibrillary cells into the sac which then proceed to ingest the denatured protein and fibrin released from the necrotic media. Some fibrillary cells organise themselves into vascular channels, whereas others secrete an extensive matrix of ground substance. With the passage of time, the lesion ages into a fibroelastic scar after transformation of the multipotential fibrillary cells into myofibroblasts and eventually fibroblasts.

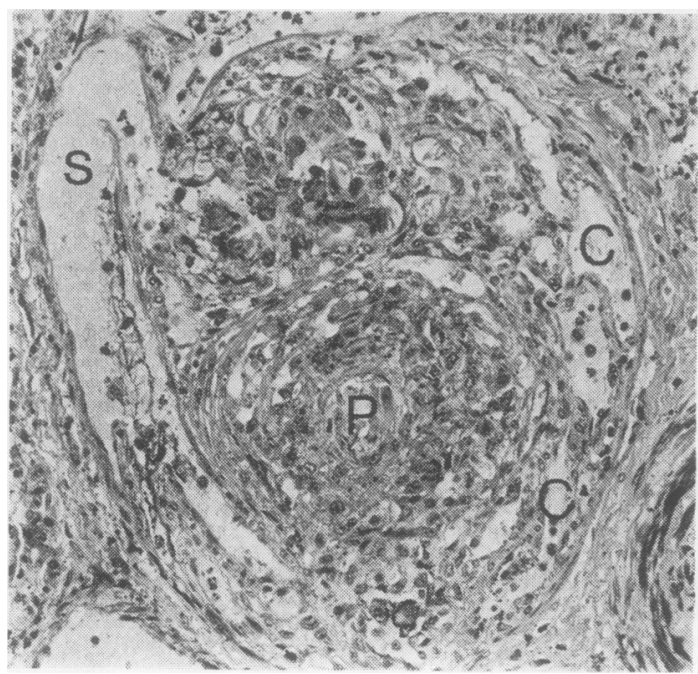

Fig 10 A plexiform lesion $(P)$ almost completely occupies the sac-like dilatation lesion (s) into which it has grown. Note that it consists of numerous plump cells with a plexus of vascular channels $(C)$ running between them (Phosphotungstic acid haematoxylin $\times 135$ ).

Any hypothesis concerning the nature and development of plexiform lesions must take into account the reason why they do not occur in mitral stenosis. Certainly fibrinoid necrosis of pulmonary arteries may occur in this condition. A significant factor may be that dilated arterial branches do not develop at terminal and side branches of muscular pulmonary arteries. This

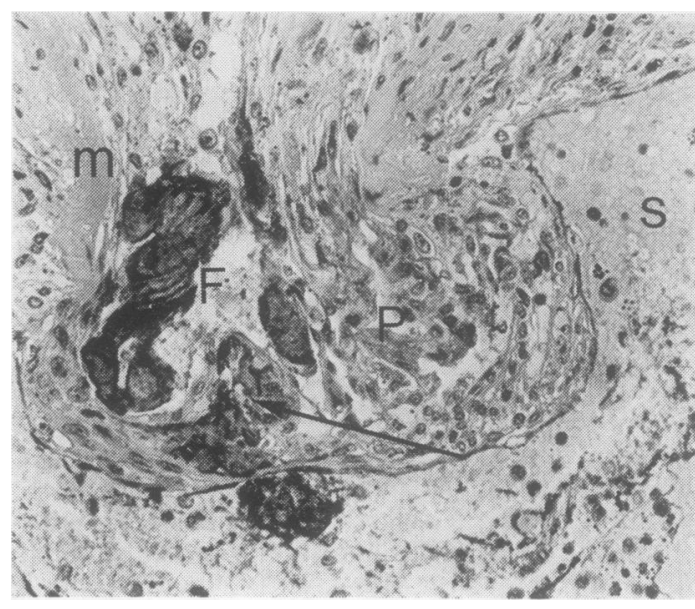

Fig 11 A cellular plexiform lesion $(P)$ growing into a dilated sac $(s)$. The media of the parent artery $(m)$ is hyaline and necrotic and adjacent to it is a clump of darkly-staining fibrin $(F)$ which extends into one of vascular channels of plexiform lesion. Smaller fragments of fibrin (arrowed) are also scattered among cells of plexiform lesion $(P T A H \times 222)$.

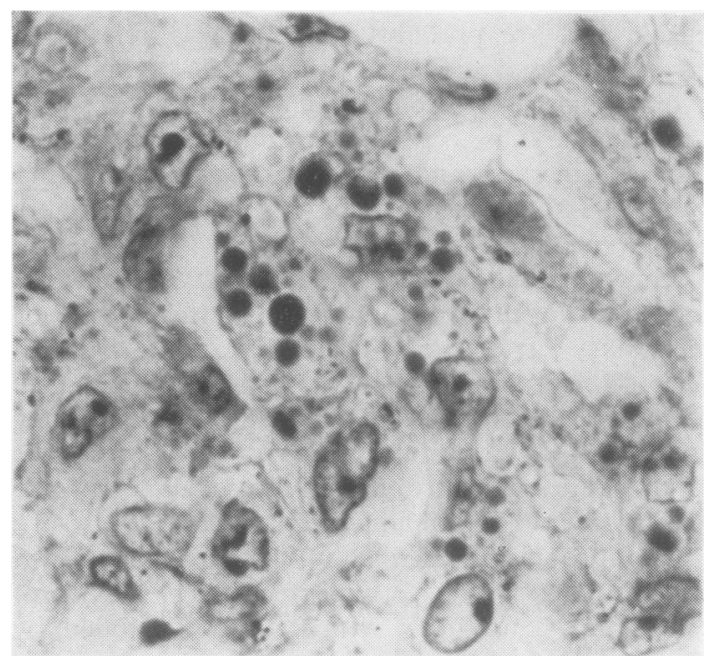

Fig 12 High magnification of cells of a plexiform lesion. Note numerous globules of darkly-staining fibrin situated within cytoplasm cells $($ PTAH $\times 1058)$.

absence of dilatation lesions in mitral stenosis may in some way be related to the presence of pulmonary venous hypertension. One can postulate that if the dilated sacs do not form, neither do the plexiform lesions.

It is possible to induce readily fibrinoid necrosis in pulmonary arteries in rats by feeding them on 8 pyrrolizidine alkaloids, yet we know that, as in 
mitral stenosis, plexiform lesions do not develop. This may simply be a species difference but it may also be related to a raised pulmonary venous pressure secondary to pulmonary venous constriction (Smith and Heath, 1978). Certainly the histological features of poisoning by $C$ spectabilis are characterised by exudative lesions in the lung parenchyma reminiscent of mitral stenosis (Smith et al, 1970).

We mention above that fibrillary cells are similar to those in the so-called "papillary tumour of heart valves." Pomerance (1961) has shown that this is not a tumour at all but is composed of tags of fibrin that become organised by fibrillary cells. They are in fact giant Lambl's excrescences. Here we have a remarkable similarity between two lesions occurring in entirely different parts of the cardiovascular system. On one hand the plexiform lesion in small dilated sacs in pulmonary arteries and on the other the papillary "tumour" in the much larger chamber of the heart. Both lesions appear to involve organisation of fibrin by fibrillary cells, both lesions age by fibroelastic change, and both present as an irregular cauliflower-like mass growing into a sac. Hence it seems likely that the cell that proliferates to form the plexiform lesion is a fibrillary cell found throughout the cardiovascular system. Whether this ubiquitous cell is a type of myofibroblast, an endothelial cell, or a true vasoformative reserve cell has yet to be determined.

We thank Dr A Paton for allowing us to study the tissues from this case. This work was carried out with the aid of a grant from the British Heart Foundation.

\section{References}

Becker, C G, and Murphy, G E (1969). Demonstration of contractile protein in endothelium and cells of heart valves, endocardium, intima, arteriosclerotic plaques and Aschoff bodies of rheumatic heart disease. American Journal of Pathology, 55, 1-37.

Bensch, K G, Gordon, G B, and Miller, L R (1964). Fibrillar structures resembling leiomyofibrils in endothelial cells of mammalian pulmonary blood vessels. Zeitschfrift Zellforschung, 63, 759-766.

Buck, R C (1961). Intimal thickening after ligature of arteries. Circulation Research, 9, 418-426.

Esterly, J A, Glagov, S, and Ferguson, D J (1968). Morphogenesis of intimal obliterative hyperplasia of small arteries in experimental pulmonary hypertension. An ultrastructural study of the role of smooth-muscle cells. American Journal of Pathology, 52, 325-347.
Gabbiani, G, Badonnel, M, and Rona, G (1975). Cytoplasmic contractile apparatus in aortic endothelial cells of hypertensive rats. Laboratory Investigation, 32, 227-234.

Gabbiani, G, Hirschel, B J, Ryan, G B, Statkov, P R, and Majno, G (1972). Granulation tissue as a contractile organ. A study of structure and function. Journal of Experimental Medicine, 135, 719-734.

Hatano, S, and Strasser, J ed (1975). Primary pulmonary hypertension. WHO, Geneva.

Hatt, P Y, Rouiller, Ch, and Grosgogeat, Y (1959). Les ultrastructures pulmonaires et le régime de la petite circulation. II $\mathrm{Au}$ cours des cardiopathies congénitales comportant une augmentation du débit sanguin intrapulmonaire. Pathologie et Biologie, 7, 515-544.

Haust, M D, More, R H, and Movat, H Z (1960). The role of smooth muscle cells in the fibrogenesis of arteriosclerosis. American Journal of Pathology, 37, 377-389.

Heath, D, and Smith, P (1978). Electron microscopy of "fibrinoid necrosis" in pulmonary arteries. Thorax, 33, 579-595.

Heath, D, and Smith, P (1979). The pulmonary endothelial cell. Thorax, 34, 200-208.

Naeye, R L (1960). "Primary" pulmonary hypertension with coexisting portal hypertension. A retrospective study of six cases. Circulation, 22, 376-384.

Parker, F, and Odland, G F (1966). A light microscopic, histochemical and electron microscopic study of experimental atherosclerosis in rabbit coronary artery and a comparison with rabbit aorta atherosclerosis. American Journal of Pathology, 48, 451481.

Pomerance, A (1961). Papillary "tumours" of the heart valves. Journal of Pathology and Bacteriology, 81, 135-140.

Poole, J C F, Cromwell, S B, and Benditt, E P (1971). Behavior of smooth muscle cells and formation of extracellular structures in the reaction of arterial walls to injury. American Journal of Pathology, 62, 391-414.

Saunders, J B, Constable, T J, Heath, D, Smith, P, and Paton, A (1979). Pulmonary hypertension complicating portal vein thrombosis. Thorax, 34, 281283.

Segel, N, Kay, J M, Bayley, T J, and Paton, A (1968). Pulmonary hypertension with hepatic cirrhosis. British Heart Journal, 30, 575-578.

Smith, P, and Heath, D (1977). Ultrastructure of hypoxic hypertensive pulmonary vascular disease. Journal of Pathology, 121, 93-100.

Smith, P, and Heath, D (1978). Evagination of vascular smooth muscle cells during the early stages of Crotalaria pulmonary hypertension. Journal of Pathology, 124, 177-183.

Smith, P, Kay, J M, and Heath, D (1970). Hypertensive pulmonary vascular disease in rats after prolonged feeding with Crotalaria spectabilis seeds. Journal of Pathology, 102, 97-106. 
Spiro, D, Lattes, R G, and Wiener, J (1965). The cellular pathology of experimental hypertension. 1. Hyperplastic arteriolar sclerosis. American Journal of Pathology, 47, 19-49.

Stein, A A, Mauro, J, Thibodeau, L, and Alley, R (1969). The histogenesis of cardiac myxomas: relation to other proliferative diseases of subendothelial vasoformative reserve cells. In Pathology Annual, edited by S C Sommers, 4, p 293. Butterworths, London.

Stovin, P G I, Heath, D, and Khaliq, U (1973). Ultrastructure of the cardiac myxoma and the papillary tumour of heart valves. Thorax, 28, 273-285.

Thomas, W A, Jones, R, Scott, R F, Morrison, E, Goodale, F, and Imai, H (1963). Production of early atherosclerotic lesions in rats characterised by proliferation of "modified smooth muscle cells." Experimental and Molecular Pathology, 2, suppl 1, $40-61$.

Wagenvoort, C A, Heath, D, and Edwards, J E (1964). Pathology of the Pulmonary Vasculature. Thomas, Springfield, Illinois.

Wissler, R W (1968). The arterial medial cell, smooth muscle or multifunctional mesenchyme? Journal of Atherosclerosis Research, 8, 201-213.

Requests for reprints to: Dr Paul Smith, Department of Pathology, Duncan Building, Royal Liverpool Hospital, Liverpool L7 8XW. 